\title{
ENCONTRO DA CAVIA PORCELLUS NATURALMENTE INFECTADA PEIO TRYPANOSOMA CRUZI EM DOMICÍLIO INFESTADO PO R PANSTRONGYLUS MEGISTUS NO ESTADO DA BAHIA, BRASIL *
}

\author{
Italo A. Sherlock, Tácito M. Muniz e Saulo P. Almeida
}

\begin{abstract}
Foram encontradas cinco cobaias Cavia porcellus naturalmente infectadas pelo Trypanosoma cruzi, em domicilio infestado pelo Panstrongylus megistus, em área endêmica para Daença de Chagas no Estado da Bahia, Brasil, entre seis exemplares examinados.

Embora os Autores não considerem a Cavia porcellus importante epidemiologicamente como reservatório doméstico da Doença de Chagas nessa área, chamam a atenção para o fato de, por ser esse roedor altamente susceptivel a infeclar-se com o $\mathrm{T}$. cruzi $e$ excelente fonte para infectar diversas espécies de triatomineos, poder em casos especiais, assumir no Brasil papel epidemiológico de destaque, como ocorre na Bolivia e no Peru.
\end{abstract}

Cerca de 150 espécies ou sub-espécies de mamíferos pertencentes as ordens Carnivora, Chiroptera, Edentata, Lagomorpha, Marsupialia, Primata e Rodentia, são enumeradas por Deane (3) e Barretto (1), como encontradas naturalmente infectadas por flagelados do tipo $T$. cruzi inclusive a cobaia Cavia porcellus.

Nesses achados, algumas espécies as vezes são consideradas importantes elos da cadeia epidemiológica da Doença de Chagas enquanto noutras oportunidades são tidas como meros reservatórios, sem impontância epidemiológica, ou ainda os dados insuficientes sobre os mesmos obtidos, não autorizam deduzir a importância de seus papéis como reservatórios da doença.

No Brasil, a única menção do encontro da cobaia naturalmente infectada, que correspondeu a um exemplar, deve-se a Correa, Silva e Schiavi (2), que examinaram 35 exemplares criados num pequeno jardim zoológico do Bosque dos Jequitibás, em Campinas, São Paulo. Esses Autores su- gerem a participação de triatomíneos na transmissão do protozoário para a cobaia.

A cobaia é tida em áreas do Peru e da Bolívia como o mais importante reservatório na cadeia epidemológica da Doença de Chagas $(4,5)$. Por isso, consideramos interessante assinalar o encontro da Cavia porcellus naturalmente infectada em domicílio infestado pelo Panstrongylus megistus, em área endêmica para Doença de Chagas no Estado da Bahia.

\section{MATERIAL E MÉTODOS}

Durante os anos de 1967 'a 1971, examinamos diversos animais domésticos que viviam nas habitaçōes infestadas por $P$. $m e-$ gistus, para surpreender o parasitemia natural pelo $T$. cruzi, na área endêmica de $\mathbf{S}$. Felipe, Estado da Bahia. Ao lado de cães, gatos e camundongos, também examiaamos seis exemplares da cobaia Cavia porcellus, que encontramos num domicílio. Essas cobaias, cinco adultos e um jovem, 
este provavelmente filho dos adultos, estavam senđo criadas em um pequeno compartimento de madeira, construído junto à parede externa do quarto de dormir. Nesse mesmo compartimento, foram então coletados inúmeros exemplares de $P$. megistus e entre eles, alguns estavam infectados por flagelados do tipo $T$. cruzi.

As cobaias foram trazidas ao laboratório e submet`ram-se a xenodiagnósticos e exames de sangue para a pesquisa direta de tripanosoma, em diversas oportun dades do ano de 1971. Os xenos foram feitos com várias espécies de triatomíneos.

Algumas dessas cobaias mantidas em laboratório se reprociuziram e servíram para outros experimentos. Outros exemplares foram doados ao Dr. Donald Minter, que os utilizou noutras observaçōes.

Inoculações de tripanosomas, tanto do sangue dessas cobaias infectadas, como obtides através de xenodiagnóstico, foram feitos em camundongos brancos para verificação da patogenicidade da cepa do tripanosoma.

\section{RESULTADOS}

Entre as seis cobaias obtidas em S. Felipe, quatro exemplares estavam infectados, duas fêmeas e um macho adultos, positivos tanto nos xenos como nas hemoscopias; um adulto fêmea somente foi positivo através de hemoscopia. Um adulto e um jovem, ambos machos, foram negativos nos dois tipos de exames.

As duas cobaias machos inicialmente negativas acusaram sempre resultados negativos, até dois meses após, quando examinados.

As cobaias positivas infectaram muito bem três espécies de triatomíneos. Em certas oportunidades, quase todos os exemplares da espécie $P$. megistus usados nos xenos ficaram positivos, atingindo uma taxa de infecção de mais de $\mathbf{9 0} \%$ dos triatomíneos utilizados. Portanto, esse roedor serve de excelente fonte de infecção para triatomíneos.

A morfologia dos flagelados observada ao microscópio, era idêntica às formas sanguíneas do $T$. cruzi observadas noutros reservatórios, indicando tratar-se dessa espécie de protozoário. A cepa desse tripanosoma, além de ser infectante para diversas espécies de triatomíneos, mostrou-se patogênica para camundongo branco, em a tendo portanto de ser considerada $T$. cruzi.

As cobaias infectadas aparentemente nãı sofriam da doença, vivendo normalmente com a as sadias e se reproduziram em diversas oportunidades. Não foram realizados estudos histo-patológicos para verif:cação do tropismo cardiomuscular do tripanosoma nessas cobaias.

\section{COMENTÁRIO E CONCLUSÕES}

O encontro da cobaia Cavia porcellus naturalmente infectada, conforme já salientamos, tem sido a sinalado na literatura. O papel de reservatório natural do $T$. cruzi e a sua importância como elo de ligação da cadeia epidemiológica da doença para o homem, pode ser bem relevante. Barretto ... (1) a considera o roedor de maior importância epidemiológica, em vista cias verificações feitas no Peru e Bolvia por Herrer (4) e Torrico (5). Estes Autores encontraram elevaơissimos índices de infecção natural pelo $T$. cruzi nesse roedor. Tais achados se tornam muito importantes em vista das condições como se apresenta esse roedor com relação a epidemiologia da Doença de Chagas naqueles países. As cobaias são ali criadas para fins alimentares dentro do domicilio, vivendo promiscuamente com os habitantes.

Pelos achados de Correa, Silva \& Schiavi (2) não podiamos ainda aquilatar a importância epidemiológica que esses animais poderiam ter entre nós, desde que o único exemplar que encontraram naturalmente infectado não vivia em contato com o homem.

$\mathrm{Na}$ área que observamos, só excepcionalmente esse animal é criado em domicílio. Em cerca de cinco mil residências que investigamos, acidentalmente encontramos os exemplares aqui observados. Dessa forma, somente ocorrendo certas condições especiais, a cobaia poderá vir a ter, entre nós, importância epidemiológica como reservatório doméstico da Doença de Chagas. Contudo, como esse roedor mostrou-se altamente susceptível à infecção natural e ótima fonte de infecção para triatomineos, fica o sobreaviso para a importância epidemiológica que poderá assumir, desde que haja o hábito de mantê-lo em domicílio nas áreas endêmicas da Doença de Chagas. 


\section{$S U M M A R Y$}

In a house infested with P. megistus in an area endemic for Chagas' disease in the State of Bahia, Brazil, five of six examined specimens of the guinea pig Cavia porcellus were found naturally infected with $T$. cruzi.

Cavia porcellus is not considered to be an epidemilogically important reservoir for $\mathbf{T}$. cruzi in this locality. However its epidemiological importance should be considered in Brazil if people breed it in dwellings in endemic areas, as in Bolivia and Peru. Cavia porcellus is highly susceptible to infection with $\mathrm{T}$. cruzi and may serve as an excellent source for infecting several especies of triatomine bugs.

\section{REF'ERÊNCIAS BIBLIOGRÁFICAS}

1. BARRETO, M. P. - Resevatórios do Trypanosoma cruzi nas Américas. Rev. Brasil. Malar. Doença Trop. 16: 527-552, 1964.

2. CORREA, R. S., SILVA, E. O. R. \& SCHIAVI, A. - Observações sobre 0 Panstrogylus megistus transmissor da moléstia de Chagas (Hemiptera, Reduviidae). Arq. Hig. \& Saúde Pública. 28: 165-174, 1963.

3. DEANE. L. M. - Animal reservoirs of Trypanosoma cruai in Brazil. Rev. Bra- sil. Malar. Doenças Trop. 16: 27-48, 1964.

4. HERRER, A. - Trypanosomíasis americana en el Perú. III - Inportancia del cobayo como reservatorio de la enfermidad de Chagas en la region sudoccidental. Rev. Med. Exper. Lima, 9: 45-55, 1955.

5. TORRICO, R. A. - Enfermedad de Chagas en Bolivia, Rev. Goina Med. 5: 375-387, 1959. 